\title{
Dietary calcium intake does not meet the nutritional requirements of children with chronic kidney disease and on dialysis
}

\author{
Louise McAlister $^{1} \cdot$ Selmy Silva ${ }^{1} \cdot$ Vanessa Shaw $^{2,3} \cdot$ Rukshana Shroff $^{1,2}$ (D)
}

Received: 27 January 2020 / Revised: 12 March 2020 / Accepted: 6 April 2020 / Published online: 8 May 2020

(C) The Author(s) 2020

\begin{abstract}
Background Adequate calcium $(\mathrm{Ca})$ intake is required for bone mineralization in children. We assessed $\mathrm{Ca}$ intake from diet and medications in children with CKD stages 4-5 and on dialysis (CKD4-5D) and age-matched controls, comparing with the UK Reference Nutrient Intake (RNI) and international recommendations.

Methods Three-day prospective diet diaries were recorded in 23 children with CKD4-5, 23 with CKD5D, and 27 controls. Doses of phosphate $(\mathrm{P})$ binders and $\mathrm{Ca}$ supplements were recorded.

Results Median dietary Ca intake in CKD4-5D was 480 (interquartile range (IQR) 300-621) vs 724 (IQR 575-852) mg/day in controls $(p=0.00002)$, providing $81 \%$ vs $108 \%$ RNI $(p=0.002)$. Seventy-six percent of patients received $<100 \%$ RNI. In CKD4-5D, 40\% dietary Ca was provided from dairy foods vs 56\% in controls. Eighty percent of CKD4-5D children were prescribed Ca-based P-binders, $15 \%$ Ca supplements, and 9\% both medications, increasing median daily Ca intake to 1145 (IQR 665-1649) $\mathrm{mg} /$ day; $177 \%$ RNI. Considering the total daily Ca intake from diet and medications, $15 \%$ received $<100 \%$ RNI, 44\% 100-200\% RNI, and 41\% > 200\% RNI. Three children (6\%) exceeded the National Kidney Foundation Kidney Disease Outcomes Quality Initiative (KDOQI) upper limit of $2500 \mathrm{mg} /$ day. None with a total Ca intake < RNI was hypocalcemic, and only one having $>2 \times$ RNI was hypercalcemic.

Conclusions Seventy-six percent of children with CKD4-5D had a dietary Ca intake $<100 \%$ RNI. Restriction of dairy foods as part of a P-controlled diet limits $\mathrm{Ca}$ intake. Additional $\mathrm{Ca}$ from medications is required to meet the KDOQI guideline of 100$200 \%$ normal recommended Ca intake.
\end{abstract}

Keywords Calcium $\cdot$ Diet $\cdot$ Bones $\cdot$ Chronic kidney disease $\cdot$ Dialysis

\section{Introduction}

Ensuring adequate calcium $(\mathrm{Ca})$ intake, along with maintaining vitamin $\mathrm{D}$ status and limiting dietary phosphate $(\mathrm{P})$ exposure, is central to the dietary management of chronic kidney

Electronic supplementary material The online version of this article (https://doi.org/10.1007/s00467-020-04571-x) contains supplementary material, which is available to authorized users.

Rukshana Shroff

Rukshana.Shroff@gosh.nhs.uk

1 Great Ormond Street Hospital for Children NHS Foundation Trust, London WC1N 3JH, UK

2 University College London Institute of Child Health, London, UK

3 University of Plymouth, Plymouth, UK disease mineral and bone disorder (CKD-MBD) in children [1]. A low Ca intake is especially of concern in children with chronic kidney disease (CKD) who require $\mathrm{Ca}$ for bone accrual and growth and to prevent fractures [2], 90\% of peak bone mass being accrued by 18 years of age [3]. Conversely, excess Ca may lead to coronary artery calcification which increases cardiovascular risk, the leading cause of death in this population $[4,5]$.

A large prospective cohort reported that children with even early CKD have a 2-3-fold higher fracture rate compared with that of their healthy peers [2]. The use of Ca-based P-binders was protective against fractures. Vascular calcification has also been identified early in CKD [6], and clinicians are increasingly favoring non-Ca-based P-binders to reduce $\mathrm{Ca}$ load, particularly for the adult dialysis population [7]. A study in young adults on dialysis [8] reported that the $\mathrm{Ca}$ intake from P-binders was nearly twice as high in those with coronary 
artery calcification compared with those without; no estimate of dietary $\mathrm{Ca}$ intake was made. However, extrapolating adult studies to pediatrics are not appropriate as children need a positive $\mathrm{Ca}$ balance [9], particularly at periods of rapid growth. Kidney Diseases Improving Global Outcomes (KDIGO) and the National Institute for Health and Care Excellence (NICE) hyperphosphatemia guidelines [10, 11] recommend that a $\mathrm{Ca}$-based binder be used as first-line treatment in controlling hyperphosphatemia in children in order to meet the $\mathrm{Ca}$ requirements of the growing skeleton. International recommendations for $\mathrm{Ca}$ intake in children with CKD $[1,12]$ suggest that the total $\mathrm{Ca}$ intake from diet and medications should be 100-200\% of normal requirements, apart from exceptional circumstances.

The aim of this study was to assess the Ca intake from food, formula feeds (FF; including infant milks, oral nutritional supplements and enteral tube formulas) and medications in children with CKD4-5D and controls. We quantified the $\mathrm{Ca}$ intake from diet, P-binders, and Ca supplements, expressed as a percentage of the UK Reference Nutrient Intake (RNI) [13], and compared this with the recommended $\mathrm{Ca}$ intake suggested by KDOQI [1]. The foods primarily contributing to $\mathrm{Ca}$ intake within this CKD population were identified and contextualized by comparison with controls and data from the UK national food consumption surveys $[14,15]$.

\section{Methods}

This is a single-center, prospective cross-sectional study that is part of a larger project assessing Ca balance in children and young adults with CKD [16]. Children from birth to 18 years of age with CKD4-5D attending renal out-patient clinics at Great Ormond Street Hospital were invited to participate. Age-matched controls were selected from siblings and friends of patients as well as children attending dermatology, ear, nose, and throat or plastic surgery minor operating lists at our hospital. All participants and/or their caregivers provided informed written consent and assent appropriate for their age. The study was approved by the research ethics committee and the NHS Health Research Authority.

Routine serum biomarkers were measured in CKD subjects at their clinic visit or prior to a mid-week hemodialysis session, and at the planned study visit or routine pre-operation assessment clinic for controls. These included serum total $\mathrm{Ca}$, ionized $\mathrm{Ca}, \mathrm{P}$, magnesium, bicarbonate, intact parathyroid hormone (PTH), 25-hydroxyvitamin D [25(OH)D], and alkaline phosphatase. PTH concentrations were measured by the Immulite 2000 Intact PTH immunoassay (Siemens Healthcare Diagnostics, Frimley, Surrey, UK). 25(OH)D concentrations were analyzed by isotope-dilution liquid chromatographytandem mass spectrometry (Waters Xevo TQ-S, Waters UK,
Elstree, Herts, UK). Ca-based P-binders and sevelamer were prescribed as per NICE hyperphosphatemia guidelines [11].

Diet diaries for 3 consecutive days (including one weekend day) were completed by each child or their parents/caregivers, following instruction by the research nurse (SS). Participants were encouraged to describe the type, amount, and cooking method of all foods and drinks consumed, including packages and labels from manufactured food items where possible. The volume and composition of FF (oral and enteral) were recorded. To reduce participant burden and simplify day to day documentation, the full description of items that were repeatedly consumed was recorded once at the start of each diary (e.g., cow's milk, semi-skimmed; bread, wholemeal thick-sliced). To ensure consistency in interpretation, one dietitian (LM) analyzed the diaries and (where necessary) converted food portions into weights using the UK Food Standard Agency Food Portion Sizes handbook [17]. Ca content was assessed with a software program, CompEat Pro (Nutrition Systems; www.compeat.co.uk), which uses the reference UK food nutrient analysis database [18]. Manufacturers' nutritional compositional data was used for FF. Calcium in drinking water (tap or mineral) was not included in the analysis, and the volume of water consumed was not recorded.

The mean daily dietary $\mathrm{Ca}$ intake from each completed 3day diary was assessed and compared with the relevant age and sex UK RNI (defined as the amount of a nutrient that is enough to meet the needs of $97.5 \%$ of a group of healthy people in the population) [13].

The median daily dietary Ca intake for 4 groups of children were compared: controls, those with CKD4-5, CKD5D (on dialysis), and all children with CKD4-5D. This was expressed as $\mathrm{mg} \mathrm{Ca} /$ day, $\mathrm{mg} \mathrm{Ca} / \mathrm{kg}$ body weight/day and as a percentage of RNI. The relative contribution of different food groups to dietary Ca intake was calculated for controls and all groups of children with $\mathrm{CKD}$. The distribution was then compared with data for children from a UK cross-sectional survey of a representative sample of the general population, the National Diet and Nutrition Survey (NDNS) [14, 15].

The $\mathrm{Ca}$ from Ca-based P-binders and $\mathrm{Ca}$ supplements was quantified based on prescribed amounts, and the total combined daily $\mathrm{Ca}$ intake from diet, $\mathrm{FF}$, and medications was calculated for all children as described above. Dietary P consumption was also assessed from the diet diaries, but it is acknowledged that this does not reliably reflect total $\mathrm{P}$ intake, as the amount from P-containing food additives cannot be quantified $[19,20]$.

\section{Statistical analysis}

Distributions of all variables were assessed for normality. Descriptive statistics are presented for demographic and clinical characteristics of the study cohort. Continuous variables are presented as medians and interquartile ranges (IQR), 
whereas frequencies and percentages are used for categorical variables. Anthropometric indices are expressed as standard deviation score (SDS) for age and sex. Comparisons of continuous variables between groups were performed using Mann-Whitney or Kruskal-Wallis tests as appropriate. Independent $t$ testing was used for between group analysis, and for group comparison of categorical variables, the Pearson chi square test or Fishers exact $t$ test was used. The relationships between continuous variables were assessed with Spearman's correlation coefficient. Statistics were calculated using SPSS Statistics 24.0 (IBM Corporation) and graphs constructed using Graph Pad Prism (version 8.3). A $p$ value of $<0.05$ was considered statistically significant, and two-sided testing of the hypothesis was used for all tests where appropriate.

\section{Results}

Baseline characteristics of the study population are described in Table 1. The groups were matched for age, sex, and ethnicity, but, as expected, the median height and weight SDS of CKD4$5 \mathrm{D}$ children was significantly lower than that of the controls. The median BMI SDS for CKD4-5D and controls were not significantly different. Ninety-two percent of participants completed a 3-day diet diary and 100\% completed 2 days.

\section{Dietary Ca intake}

The median dietary $\mathrm{Ca}$ intake in CKD4-5D was 480 (IQR $300-621$ ) vs 724 (IQR 575-852) $\mathrm{mg} /$ day in controls $(p=$ $0.00002)$, providing $81 \%$ vs $108 \%$ RNI for age $(p=0.002)$. This equates to 19 (IQR 14-40) vs 18 (IQR 13-45) $\mathrm{mg} \mathrm{Ca} /$ $\mathrm{kg} /$ day in CKD4-5D vs controls. Accounting for the growth deficit in CKD4-5D (median weight and height SDS - 1.0 and -1.6 respectively), the percentage intake was $80 \%$ (IQR 58 118 ) vs $108 \%$ (IQR 75-176) of RNI for height age $(p=0.008)$.

Seventy-six percent of children with CKD4-5D received $<$ $100 \%$ RNI for Ca. Two of the controls (but none of those with CKD4-5D) had a dietary Ca intake exceeding $2 \times$ RNI for age. Comparing dietary $\mathrm{Ca}$ intake in CKD4-5D with controls by age, children under 10 years with CKD4-5D had significantly lower dietary $\mathrm{Ca}$ as \% RNI, but this difference was not significant in those over 10 years (Fig. 1). Dietary Ca intake in CKD4-5D and controls expressed as $\mathrm{mg} / \mathrm{kg} /$ day, showed a negative correlation with age $\left(\mathrm{R}^{2}=-0.45\right.$ vs $R^{2}=0.66$. respectively; Supplementary Fig. 1). There was no difference in the $\mathrm{Ca}$ intake (\% RNI) in those with CKD4 vs CKD5 ( $p=$ $0.06)$ or between CKD4-5 and CKD5D $(p=0.42)$.

Twelve out of 23 (52\%) children on dialysis were exclusively $\mathrm{FF}$, achieving $89 \% \mathrm{RNI} \mathrm{Ca}$, which is comparable with that of controls $(p=0.08)$. Twelve $(26 \%)$ of children with CKD4-5D received partial FF, that provided $31(23-40) \%$ of dietary Ca intake or 28 (13-51)\% RNI. Those children with CKD4-5D not exclusively FF had a lower median Ca intake (79\% RNI), and this was significantly lower than controls $(p=0.0009)$.

\section{Main dietary sources of $\mathrm{Ca}$}

In controls, dairy foods and cereals (including grains made into pasta, rice, breads, breakfast cereals and biscuits) were the main sources of dietary Ca, contributing $56 \%$ and $27 \%$ respectively of intake, similar to that reported for the UK population from the NDNS [14, 15] (Fig. 2). Excluding those who were exclusively FF, children with CKD4-5D had a significantly lower proportion from dairy foods (40\%) and an increased contribution from cereals (33\%). When the Ca provided by FF was included, the contribution from dairy foods further reduced to $26 \%$ of total dietary intake.

The daily $\mathrm{P}$ intake and contribution of different foods to $\mathrm{P}$ intake are shown in Supplementary Tables 1 and 2. The significant contribution of dairy foods and cereals to both $\mathrm{Ca}$ and $\mathrm{P}$ intakes is reflected by the close correlation between $\mathrm{Ca}$ and $P$ intake (as a \% RNI) in the children with CKD4-5D $\left(p<0.0001, R^{2}=0.51\right.$; Fig. 3$)$.

\section{All CKD}

\section{Total Ca intake from diet and medications}

$80 \%$ (37/46) of children with CKD4-5D were prescribed Ca-based P-binders, including 2 children who received Ca-based P-binders and sevelamer (Table 2). No child was on a non-Ca-based P-binder alone. Seven children (15\%) needed Ca supplements, and 4 (9\%) were on both $\mathrm{Ca}$ supplements and Ca-based P-binders. Three children requiring $\mathrm{Ca}$ supplements also received a high dialysate Ca $(1.75 \mathrm{mmol} / \mathrm{L}$ compared with the standard $1.25 \mathrm{mmol} / \mathrm{L}$; 2 on HD and 1 on PD). There was no correlation between age and the type of Ca-based P-binder used.

The $\mathrm{Ca}$ intake from diet and all medications as \% RNI is shown in Fig. 4. Including the $\mathrm{Ca}$ from medications increased the median total $\mathrm{Ca}$ intake to 177 (IQR 119270) \% RNI, medications contributing 59.5 (IQR 29.574.0) \% of total daily $\mathrm{Ca}$ intake. For children with CKD4-5, the relative contribution from medications to total calcium intake was highest in those with the lowest eGFR $(p=0.01)$. In CKD4-5D patients, the total $\mathrm{Ca}$ intake was $<100 \%$ RNI in $15 \%, 100-200 \%$ RNI in $44 \%$ and $>2 \times$ RNI in $41 \%$. Three $(6 \%)$ of the CKD4-5D patients exceeded the KDOQI recommended upper limit of $2500 \mathrm{mg} \mathrm{Ca} /$ day. 
Table 1 Demographics, anthropometry and routine clinical measures for the study population and controls

\begin{tabular}{|c|c|c|c|c|}
\hline & CKD4-5 $(n=23)$ & CKD5D (dialysis) $(n=23)$ & All CKD (CKD4-5D) $(n=46)$ & Controls $(n=27)$ \\
\hline \multicolumn{5}{|l|}{ Age (years) } \\
\hline Median (IQR) & $10.2(6.5-12.5)$ & $6.9(2.5-14.1)$ & $9.1(4.8-14.1)$ & $10.1(4.8-14.7)$ \\
\hline $\operatorname{Sex}(\mathrm{F}, \%)$ & $7(30 \%)$ & $13(57 \%)$ & $20(43 \%)$ & $15(56 \%)$ \\
\hline \multicolumn{5}{|l|}{ Underlying kidney disease } \\
\hline CAKUT/cystic/glomerulonephritis/others & $19 / 3 / 1 / 0$ & $13 / 1 / 3 / 6$ & $32 / 4 / 4 / 6$ & - \\
\hline \multicolumn{5}{|l|}{ Ethnicity } \\
\hline Caucasian/Asian/African/Arabic/mixed & $21 / 2 / 0 / 0 / 0$ & $9 / 9 / 4 / 1 / 0$ & $30 / 11 / 4 / 1 / 0$ & $18 / 5 / 1 / 0 / 3$ \\
\hline $\mathrm{eGFR}^{*}\left(\mathrm{~mL} / \mathrm{min} / 1.73 \mathrm{~m}^{2}\right)$ median & $16(11-23)$ & - & - & $120(110-128)$ \\
\hline \multicolumn{5}{|l|}{ Dialysis } \\
\hline Mode (PD/HD) & - & $8 / 15$ & - & - \\
\hline Time on dialysis (years) & - & $1.21(0.4-3.3)$ & - & - \\
\hline \multicolumn{5}{|l|}{ Anthropometry } \\
\hline Weight SDS & -0.2 & -1.8 & -1.0 & 0.4 \\
\hline Height SDS & -0.8 & -2.0 & -1.6 & 0.4 \\
\hline BMI SDS & 0.6 & -0.1 & 0.4 & 0.3 \\
\hline \multicolumn{5}{|l|}{ Vitamin D analogues $(n, \%)$} \\
\hline Colecalciferol & $7(30 \%)$ & $12(52 \%)$ & $19(41 \%)$ & - \\
\hline Alfacalcidol & $22(96 \%)$ & $20(87 \%)$ & $42(91 \%)$ & - \\
\hline Both & $6(26 \%)$ & $11(48 \%)$ & $17(37 \%)$ & - \\
\hline \multicolumn{5}{|l|}{ Vitamin D status** } \\
\hline Median 25(OH)D (nmol/L) & $85(72-146)$ & $148(70-115)$ & $111(72-172)$ & $62(41-76)$ \\
\hline$<50(\%)$ & 19 & 17 & 18 & 33 \\
\hline $50-75(\%)$ & 24 & 17 & 21 & 33 \\
\hline$>75(\%)$ & 57 & 66 & 61 & 33 \\
\hline Serum calcium (mmol/L) & $2.48(2.43-2.54)$ & $2.49(2.39-2.55)$ & $2.49(2.41-2.56)$ & $2.33(2.29-2.41)$ \\
\hline Serum ionized calcium $(\mathrm{mmol} / \mathrm{L})$ & $1.21(1.17-1.26)$ & $1.22(1.18-1.29)$ & $1.20(1.17-1.24)$ & $1.19(1.13-1.22)$ \\
\hline Serum phosphate $(\mathrm{mmol} / \mathrm{L})$ & $1.46(1.32-1.46)$ & $1.7(1.25-1.90)$ & $1.59(1.29-1.80)$ & $1.46(1.37-1.64)$ \\
\hline PTH (pmol/L) & $6.9(3.2-16.5)$ & $21.9(8.3-44.3)$ & $12.2(4.2-32.1)$ & $4(2.4-7.18)$ \\
\hline Alkaline phosphatase (U/L) & $179(133-242)$ & $247(174-350)$ & $201(154-282)$ & $181(120-292)^{* * *}$ \\
\hline
\end{tabular}

*Schwartz formula [39]

**Vitamin D status, $<50 \mathrm{nmol} / \mathrm{L}$, deficient; 50-75 nmol/L, insufficient; > $75 \mathrm{nmol} / \mathrm{L}$, sufficient [40]

$* * * n=18$

$I Q R$ interquartile range, $C A K U T$ congenital anomalies of kidney and urinary tract, $e G F R$ estimated glomerular filtration rate, $P D$ peritoneal dialysis, $H D$ hemodialysis, $S D S$ standard deviation score, $B M I$ body mass index

\section{Ca intake and serum biochemistry}

There were no significant differences in serum calcium between those exclusively FF and those not on FF. Serum Ca, ionized $\mathrm{Ca}, \mathrm{PTH}$, or alkaline phosphatase did not reflect dietary or total $\mathrm{Ca}$ intake. None of the 7 patients with a total $\mathrm{Ca}$ intake below RNI was hypocalcemic (albumin-corrected serum $\mathrm{Ca}<2.0 \mathrm{mmol} / \mathrm{L}$ ), and only 1 of the 19 with a total $\mathrm{Ca}$ intake $>$ $2 \times$ RNI was hypercalcemic (albumin-corrected serum $\mathrm{Ca}>$ $2.6 \mathrm{mmol} / \mathrm{L}$ ). There was no relationship between vitamin $\mathrm{D}$ status and other measures of $\mathrm{Ca}$ status or bone health (serum $\mathrm{Ca}$, ionized calcium, $\mathrm{PTH}$, or alkaline phosphatase).

\section{Discussion}

In this study, we have shown that $\mathrm{Ca}$ intake from diet alone was inadequate in $76 \%$ of children with CKD4-5D, median dietary $\mathrm{Ca}$ intake being $81 \% \mathrm{RNI}$ for age, and significantly lower than that for age-matched controls. Phases of rapid growth in childhood and adolescence are critical periods for bone mass accrual [3], giving rise to a greatly increased $\mathrm{Ca}$ requirement [9]. Studies in healthy pre-pubertal children receiving calcium supplementation showed increase in bone mass and augmented bone response to physical activity compared with non-supplemented controls [21, 22]. High calcium 
Fig. 1 Dietary Ca intake in children with CKD4-5D and controls for different age groups. Violin plots with the thick bar representing the median and thinner lines representing inter quartile range. Children are categorized into four age groups. The ANOVA compares $\mathrm{Ca}(\%$ RNI) in children of all age groups (for controls $p=0.02$; for CKD4 5D $p=0.19$ )

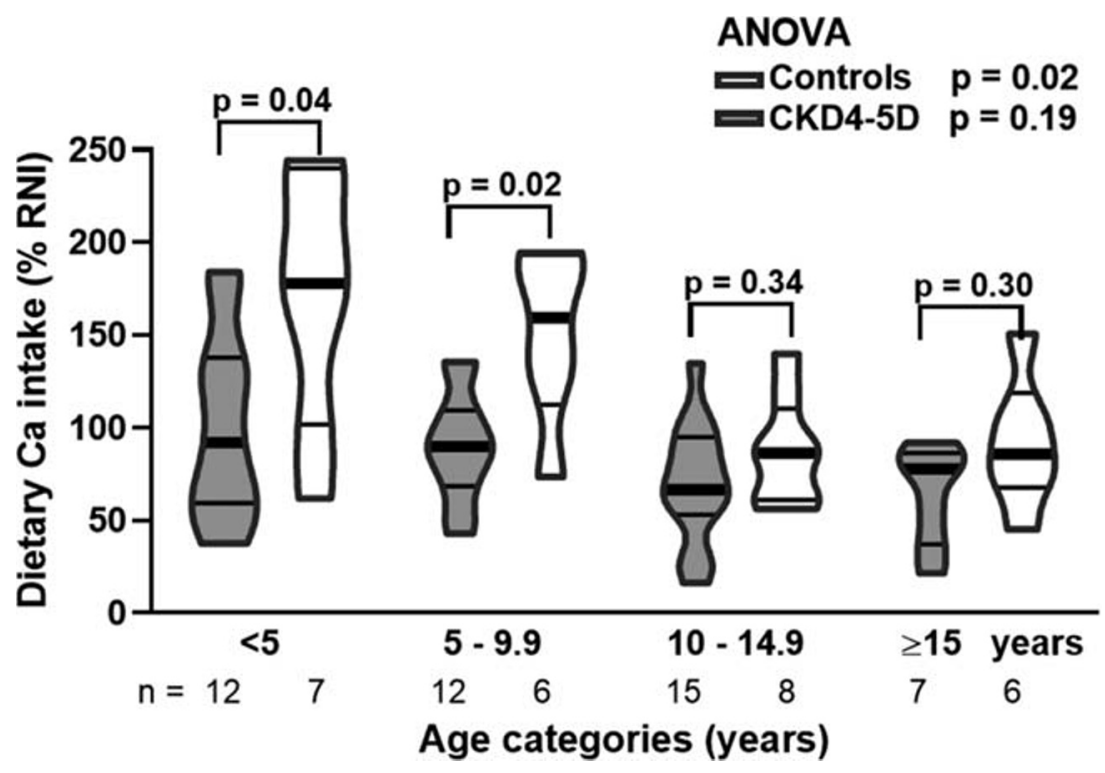

intakes seem to be protective against fractures in healthy adolescents [23]. Our data support the KDIGO [10] and NICE [11] recommendations for the use of Ca-based P-binders as first-line treatment for hyperphosphatemia in children with CKD and on dialysis.

These findings are in agreement with the Growth Failure in Children with Renal Disease (GFRD) study [24], where children with CKD achieved a $\mathrm{Ca}$ intake of $80 \%$ of normal requirements for age. Other studies have described similar or even lower $\mathrm{Ca}$ intakes [25-27], even from CKD stage 3
[28]. It is likely that a poor appetite also contributes to the reduced $\mathrm{Ca}$ intake in those with $\mathrm{CKD}$.

The relative contribution of different food groups to total dietary $\mathrm{Ca}$ intake in pediatric $\mathrm{CKD}$ has not been previously reported. The lower proportion of dietary $\mathrm{Ca}$ in CKD4-5D from dairy foods (40\% vs 56\% in controls), and the lower P intake assessed from the diet diaries, suggests that the reduction in dietary $\mathrm{Ca}$ intake may be an inadvertent consequence of advice to reduce $\mathrm{P}$ intake. Limiting dairy foods (along with avoidance of $\mathrm{P}$ food additives) often constitutes the first-line
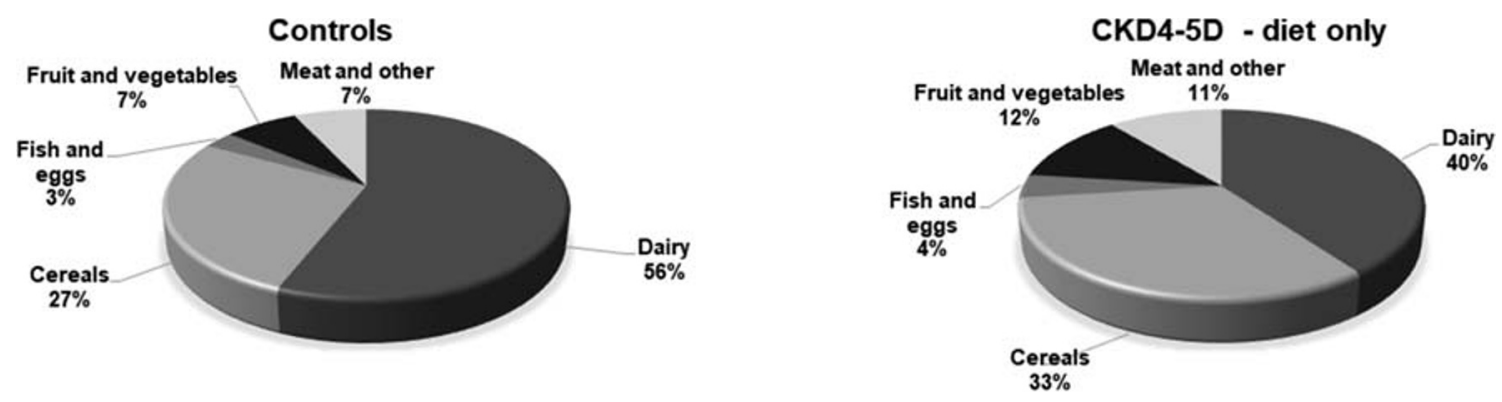

CKD4-5D - diet and formula feeds* (*oral and enteral)

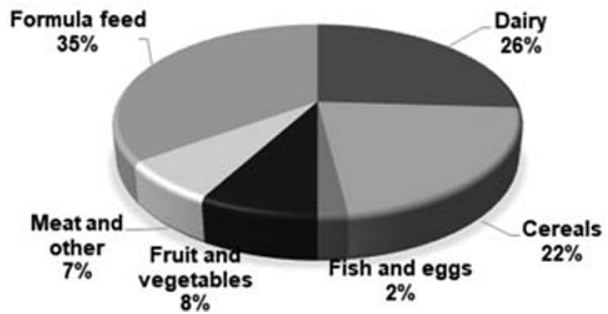

Fig. 2 Main food groups contributing to Ca intake (\% total intake per day), in controls and CKD4-5D. Ca contributed from diet alone and diet plus formula feeds are shown separately 


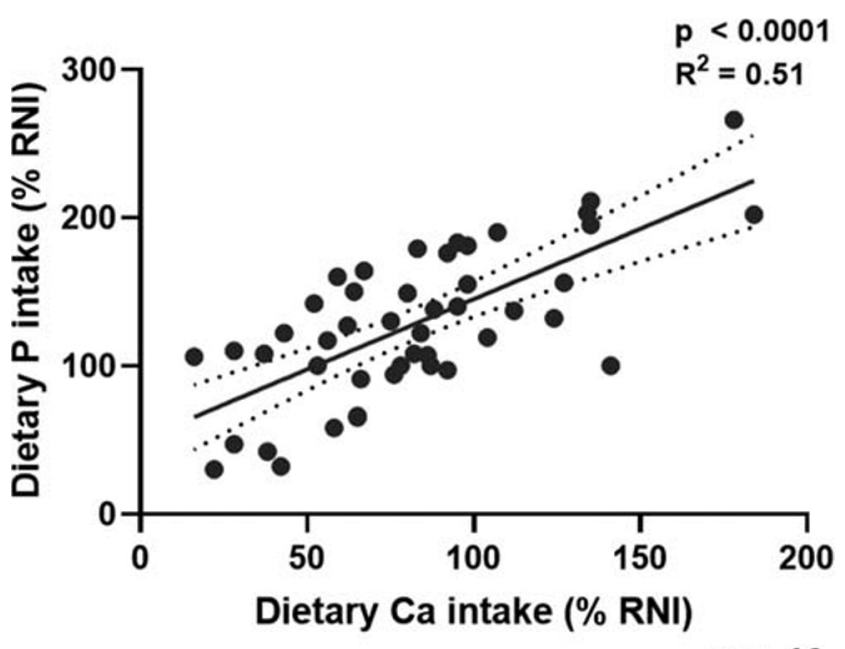

$\mathrm{n}=\mathbf{4 6}$

Fig. 3 Relationship between dietary $\mathrm{Ca}$ and $\mathrm{P}$ intake in children with CKD4-5D. The linear regression with $95 \%$ confidence intervals is shown

intervention for serum $\mathrm{P}$ control. In this cohort, all the children with CKD had been advised on dietary phosphate restriction. Excluding those exclusively on FF, cereals contributed $33 \%$ and $27 \%$ of dietary $\mathrm{Ca}$ intake in CKD and controls, respectively. Of note, mandatory fortification of most flour in the UK [29] (and the voluntarily fortification of foods such as breakfast cereals) increases the contribution of cereals to daily $\mathrm{Ca}$ intake in our patients. However, in countries where fortification is not common practice, the $\mathrm{Ca}$ intake in this population may be even lower. The contribution of FF to dietary $\mathrm{Ca}$ intake has not been previously studied. Children with CKD who were exclusively fed FF achieved a higher dietary $\mathrm{Ca}$ intake which was comparable with that of controls $(p=$ 0.08 ).

A previous study reported a reduction in dietary $\mathrm{Ca}$ intake as renal function declines through all CKD stages [25]; we found this in those with CKD4-5, but not in those on dialysis, possibly due to the higher use of FF in the latter group. This finding emphasizes the importance of offering enteral tube feeding to improve overall nutrition (including $\mathrm{Ca}$ intake) in those struggling with a poor oral intake, as recommended by the Pediatric Renal Nutrition Taskforce (PRNT) [30]. Our results suggest a greater reliance on Ca-based medications with advancing CKD, perhaps as dietary $\mathrm{P}$ restrictions increase or are more strictly enforced, inadvertently reducing dietary $\mathrm{Ca}$ intake.

No previous dietary studies in children with CKD have quantified the contribution from Ca-containing medications. We have shown $76 \%$ of CKD4-5D patients received insufficient dietary $\mathrm{Ca}$, and that $\mathrm{Ca}$-based P-binders and $\mathrm{Ca}$ supplements improved $\mathrm{Ca}$ intake to a median of $177 \%$ RNI. While both KDIGO and NICE recommend Ca-based P-binders should be the first-line treatment for hyperphosphatemia in children with CKD $[10,11]$, the absorption of Ca from these binders is uncertain (reported to be between 20 and 30\%). Absorption is generally lower than that from food, varies with the timing of administration in relation to food, and differs between Ca-carbonate and Ca-acetate [7, 31]. In addition, $\mathrm{Ca}$ absorption varies between 15 and $40 \%$ depending on the individual's vitamin D status [32]. This variable absorption (which also applies to food-derived $\mathrm{Ca}$ ) was not adjusted for in our analysis and has been identified as a future research need by the PRNT in their clinical practice recommendations for $\mathrm{Ca}$ and $\mathrm{P}$ for CKD2-5D [12].

Taking into account body size, dietary Ca intake, expressed as mg per kg body weight, decreased with increasing age in controls and children with CKD4-5D (as shown in Supplementary Fig.1). It is difficult to attribute any importance to this as Ca requirements are influenced by a number of factors that are dependent on age rather than weight. The reported difference in dietary Ca intake (as a \% RNI) between controls and those with CKD4-5D was still significant when adjusted for height age.

RNI for Ca was not met by $44 \%$ of controls, suggesting that a low $\mathrm{Ca}$ intake in the general pediatric population may be a concern, particularly in those over 10 years of age. This finding was also reflected in the latest report from the NDNS, where an increasing proportion of UK children in the age group 11 to 18 years had an insufficient dietary $\mathrm{Ca}$ intake [33]. The wide variation in published international
Table 2 Use of phosphate binders, calcium supplements, and phosphate supplements

\begin{tabular}{llll}
\hline Medications & All CKD $(n=46)$ & CKD4-5 (n=23) & CKD5D (n=23) \\
\hline Phosphate binder & $37(80 \%)$ & 21 & 16 \\
Ca-based binders alone & $35(76 \%)$ & 20 & 15 \\
Calcium carbonate/calcium acetate & $16 / 19$ & $12 / 7$ & $4 / 12$ \\
Ca-based binder and sevelamer & $2(4 \%)$ & 1 & 1 \\
Calcium supplements & $7(15 \%)$ & 2 & 5 \\
Calcium carbonate & 5 & 0 & 5 \\
Calcium glubionate and calcium lactobionate & 2 & 2 & 0 \\
Ca-based phosphate binder and Ca supplement & $4(9 \%)$ & 2 & 2 \\
Phosphate supplement & $5(11 \%)$ & 0 & 5 \\
\hline
\end{tabular}


Fig. $4 \mathrm{Ca}$ intake from diet and medications expressed as a percentage of reference nutrient intake (\% RNI) for age
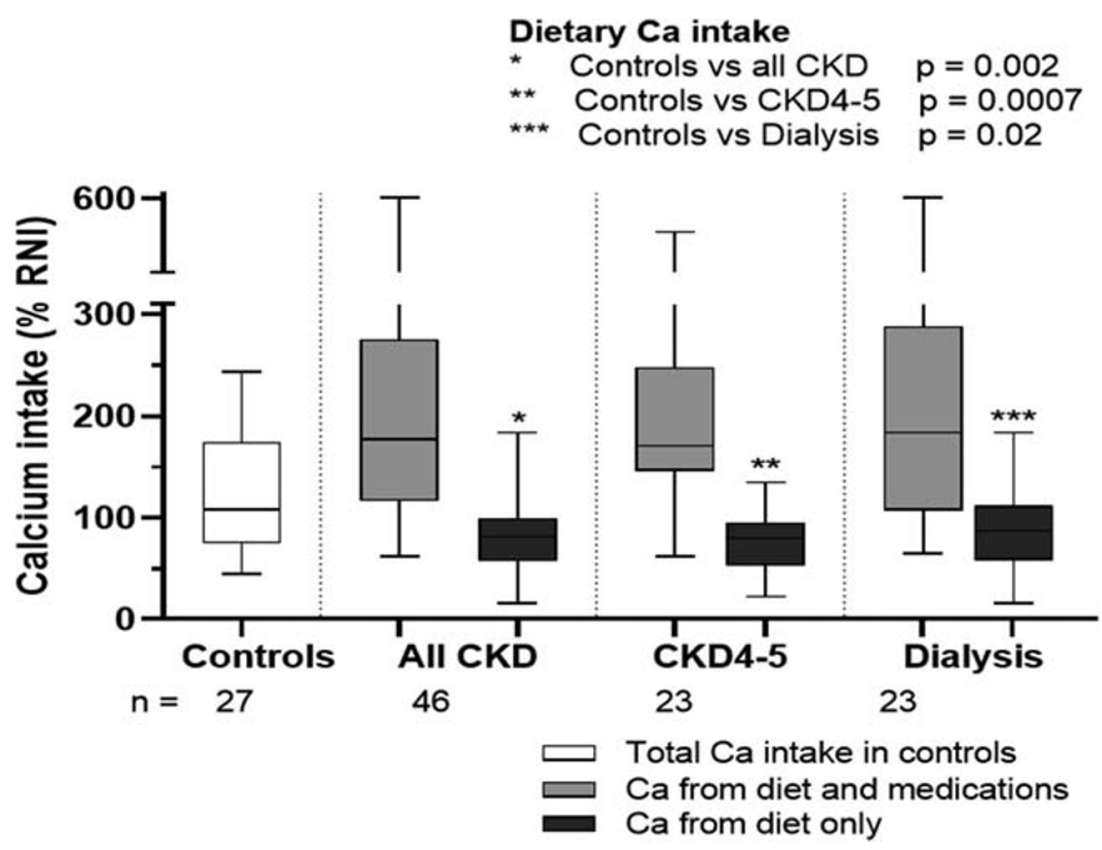

requirements for $\mathrm{Ca}$ [12] and the increased availability of data on $\mathrm{Ca}$ balance in children may suggest that the UK RNI figures which were published in 1991 are no longer an appropriate reference against which to benchmark $\mathrm{Ca}$ intake. This has been addressed by PRNT [12] who propose a new term, Suggested Dietary Intake (SDI), which reflects the range of recently published international requirements derived using the most reliable methods for assessing mineral status (and does not include the UK RNI). Only $11 \%$ of our CKD cohort had a dietary $\mathrm{Ca}$ intake within the SDI, compared with $24 \%$ achieving UK RNI as the latter is set lower for most age groups. Although international guidelines [10-12] recommend that clinical decisions are based on serum $\mathrm{Ca}$ (or ionized $\mathrm{Ca}$ ) levels, none of the 7 children with a total $\mathrm{Ca}$ intake below RNI was hypocalcemic, and only one patient having $>2 \times$ RNI was hypercalcemic, suggesting that serum $\mathrm{Ca}$ may not be a useful guide to the adequacy of $\mathrm{Ca}$ intake. The true $\mathrm{Ca}$ requirements for any individual depend on their age, growth, and rate of bone turnover [12]. To fully interpret our results, and understand the implications of high and low $\mathrm{Ca}$ intakes in children with $\mathrm{CKD}$, careful $\mathrm{Ca}$ balance studies are needed to determine $\mathrm{Ca}$ absorption, state of bone mineralization, and fate of the ingested $\mathrm{Ca}$. Meanwhile, as recommended by KDIGO, trends in $\mathrm{Ca}, \mathrm{P}, \mathrm{PTH}$, and ALP, taken together, are the best available measure for the clinical management of MBD [10]. Indeed, as shown in a recent study in children and young adults with CKD 4-5D [34], tibial cortical bone mineral density (BMD) was negatively associated with parathyroid hormone (PTH; $r=-0.44, p<0.001)$ and alkaline phosphatase (ALP; $r=-0.22, p=0.03$ ) and positively with serum calcium $(r=0.33, p=0.001)$. On multivariable linear regression PTH, ALP and calcium together predicted $57 \%$ of variability in tibial cortical BMD measured by peripheral quantitative CT scan, whereas dual energy X-ray absorptiometry did not correlate with biochemical measures.

Forty-one percent of our CKD4-5D cohort received > $200 \%$ RNI for $\mathrm{Ca}$ as a result of the contribution from $\mathrm{Ca}$ based P-binders. However, in this study, we did not record adherence to medications and this may have resulted in an overestimation of total $\mathrm{Ca}$ intake, as adherence to P-binder medication is notoriously poor $[35,36]$. It is also not certain how much calcium is absorbed from these binders [7]. In clinical practice, in the presence of high serum calcium, we would carefully check the patient's dosage and timing of administration of Ca-based P-binders in relation to their dietary phosphate intake. In our experience, patient education often results in a lower overall dosage, when binders are being used unnecessarily with low phosphate meals. In addition, patients would be instructed not to give calcium carbonate at the same time as ranitidine or other $\mathrm{H} 2$ blocker as gastric acidity is required for the dissociation of calcium carbonate and its phosphate-binding effect [7].

Limitations of our study include the incompleteness of the diet diaries (3 CKD4-5D and 3 controls completed only 2 rather than 3 days). The use of a semi-quantitative prospective 3-day diet diary is considered to be an appropriate dietary assessment tool for Ca or P intake [12, 37], but imposes a high participant burden with possibly incomplete or selective recording [37, 38]. In an attempt to limit potential errors due to coding and interpretation of the diaries, a single dietitian performed all the analyses. Nutrient databases and dietary assessment software packages to calculate $\mathrm{Ca}$ intake are considered reasonably accurate when compared with direct chemical analyses [38], but a food database does not fully account for $\mathrm{Ca}$ intake from food additives, food fortification, or from 
drinking water. Ca intake from dialysate was also not included in the $\mathrm{Ca}$ analysis.

In conclusion, $76 \%$ of the CK4-5D study population from a large pediatric tertiary care hospital had a dietary $\mathrm{Ca}$ intake below $100 \%$ RNI for age. A reduction in Ca intake from dairy foods is likely to account for this. In our cohort, $80 \%$ of patients had Ca-based P-binders and $9 \%$ also had Ca supplements, increasing $\mathrm{Ca}$ intake to $177 \% \mathrm{RNI}$ and thus meeting the KDOQI guidelines for CKD of 100-200\% recommended intakes for the normal population. Just as with healthy children, an adequate $\mathrm{Ca}$ intake is required to meet the needs of the growing skeleton in children with CKD.

Acknowledgments I am grateful to Dr. Graeme O'Connor for statistical advice.

Funding information RS is funded by a National Institute for Health Research (NIHR) Career Development Fellowship for this research project. This publication presents independent research funded by the National Institute for Health Research (NIHR). The views expressed are those of the author(s) and not necessarily those of the NHS, the NIHR, or the Department of Health and Social Care. A part of the work took place in the Biomedical Research Centre at Great Ormond Street Hospital for Children NHS Foundation Trust and University College London.

Open Access This article is licensed under a Creative Commons Attribution 4.0 International License, which permits use, sharing, adaptation, distribution and reproduction in any medium or format, as long as you give appropriate credit to the original author(s) and the source, provide a link to the Creative Commons licence, and indicate if changes were made. The images or other third party material in this article are included in the article's Creative Commons licence, unless indicated otherwise in a credit line to the material. If material is not included in the article's Creative Commons licence and your intended use is not permitted by statutory regulation or exceeds the permitted use, you will need to obtain permission directly from the copyright holder. To view a copy of this licence, visit http://creativecommons.org/licenses/by/4.0/.

\section{References}

1. KDOQI Clinical practice guideline for nutrition in children with CKD 2008 (2009). Am J Kidney Dis 53 (3, Suppl 2):S11-104

2. Denberg MR, Kumar J, Jemielita T, Brooks ER, Skversky A, Portale AA, Salusky IB, Warady BA, Furth SL, Leonard MB (2016) Fracture burden and risk of fractures in childhood CKD: results from the CKiD cohort study. J Am Soc Nephrol 27(2): 543-550

3. Baxter-Jones AD, Faulkner RA, Forwood MR, Mirwald RL, Bailey DA (2011) Bone mineral accrual from 8 to 30 years of age: an estimation of peak bone mass. J Miner Res 26(8):1729-1739

4. Shroff R, Long DA, Shanahan C (2013) Mechanistic insights into vascular calcification in CKD. J Am Soc Nephrol 24:179-189

5. Bertram JF, Goldstein SL, Pape L, Schaefer F, Shroff R, Warady BA (2016) Kidney disease in children: latest advances and remaining challenges. Nat Rev Nephrol 12:182-191 Invited viewpoint article for World Kidney Day 2016

6. Shroff RC, Donald AE, Hiorns MP, Watson A, Feather S, Milford D, Ellins EA, Storry C, Ridout D, Deanfield J, Rees L (2007)
Mineral metabolism and vascular damage in children on dialysis. JASN 18(11):2996-3003

7. Rees L, Shroff RC (2010) Phosphate binders in CKD: chalking out the differences. Pediatr Nephrol 25:295-394

8. Goodman WG, Goldin J, Kuizon BD, Yoon C, Gales B, Sider D, Wang Y, Chung J, Emerick A, Greaser L, Elashoff RM, Salusky IB (2000) Coronary artery calcification in young adults with end-stage renal disease who are undergoing dialysis. N Engl J Med 342: $1478-1483$

9. Matkovic V, Heaney RP (1992) Calcium balance during human growth: evidence for threshold behavior. Am J Clin Nutr 55(5): 992-996

10. Ketteler M, Block GA, Evenepoel P, Fukagawa M, Herzog CA, McCann L, Mow SM, Shroff R, Tonelli MA, Toussaint ND, Vervloet MG, Leonard MB (2017) Executive summary of the 2017 KDIGO chronic kidney disease-mineral and bone disorder (CKD-MBD) guideline update: what's changed and why it matters. Kidney Int 92(1):26-36

11. NICE clinical guideline 157 (2013): Hyperphosphataemia in chronic kidney disease. https://wwwniceorguk/guidance/CG157 Accessed 17 Nov 2019

12. McAlister L, Pugh P, Greenbaum L, Haffner D, Rees L, Anderson C, Desloovere A, Nelms C, Oosterveld M, Paglialonga F, Polderman N, Qizalbash L, Renken-Terhaerdt J, Tuokkola J, Warady B, Vande Walle J, Shaw V, Shroff R (2020) The dietary management of calcium and phosphate in children with CKD stages 2-5 and on dialysis - clinical practice recommendation from the Pediatric Renal Nutrition Taskforce. Pediatr Nephrol 35:501-518

13. Dietary reference values for food energy and nutrients for the United Kingdom (1991). COMA, Department of Health, London, HMSO

14. National Diet and Nutrition Survey: children ages $1 \frac{1}{2}$ to $4 \frac{1}{2}$ years. Volume 1: report of the diet and nutrition survey (1995). London, HMSO

15. National Diet and Nutrition Survey: Young people aged 4 to 18 years. Volume report of the diet and nutrition survey (2000). London, The Stationery Office

16. Shroff R, Kolevika A, Heuser A, Lalayiannis A et al (2019) Stable calcium isotopes: a novel biomarker of bone mineralization in children with chronic kidney disease. Pediatr Nephrol 34:2155

17. Food Portion Sizes (MAFF Handbook) 3rd edition (2002). Editors: Mills H, Patel S, Crawley H. Food Standards Agency, London, The Stationery Office

18. McCance \& Widdowson's The composition of foods: seventh summary edition (2014) Cambridge, Royal Society of Medicine. https:// doi.org/10.1039/9781849737562-00001.

19. Hannah H, Roe M, Warthon-Medina M, Pinchen H, Barrett M, Perry S (2018) Phosphorus in food: limitations of food composition data. J Kid Care 3(6):362-267

20. Borg L (2019) Inclusion of phosphorus in the nutritional facts label. Clin J Am Soc Nephrol 14(1):139-140

21. Johnston CC, Miller JZ, Slemenda CW, Reister TK, Hui S, Christian JC, Peacock M (1992) Calcium supplementation and increases in bone mineral density in children. N Engl J Med 327(2): $82-87$

22. Bonjour JP, Carrie AL, Ferrari S, Clavien H, Slosman D, Theintz G, Rizzoliet R (1997) Calcium-enriched foods and bone mass growth in prepubertal girls: a randomized, double-blind, placebo-controlled trial. J Clin Invest 99:1287-1294

23. Wyshak G, Frisch RE (1994) Carbonated beverages, dietary calcium, the dietary calcium/phosphorus ratio, and bone fractures in girls and boys. J Adolesc Health 15:210-215

24. Trachtman H, Chan JC, Boyle R, Farina D, Baluarte HJ, Chinchilli VM, Dresner IG, Feld LG (1995) The relationship between calcium, phosphorus, and sodium intake, race, and blood pressure in 
children with renal insufficiency: a report of the Growth Failure in Children with Renal Diseases (GFRD) Study. JASN 6(1):126-131

25. Norman LJ, Macdonald IA, Watson AR (2004) Optimising nutrition in chronic renal insufficiency - progression of disease. Pediatr Nephrol 19(11):1253-1261

26. Gupta A, Mantan M, Sethi M (2016) Nutritional assessment in children with chronic kidney disease. Saudi Journal of Kidney Diseases and Transplantation 27(4):733-739

27. Kim H, Lim H, Choue R (2014) Compromised diet quality is associated with decreased renal function in children with chronic kidney disease. Clin Nutr Res 3(2):142-149

28. Rätsch IM, Catassi C, Verrina E, Gusmano R, Appiani A, Bettinelli A, Picca S, Rizzoni G, Fabian-Bach C, Wingen AM, Mehls O, Giorgi PL (1992) Energy and nutrient intake of patients with mild-to-moderate chronic renal failure compared with healthy children: an Italian multicentre study. Eur J Pediatr 151(9):701-705

29. The bread and flour regulations no. 141 (1998); https://www. legislation.gov.uk/uksi/1998/141 Accessed 17 Nov 2019

30. Shaw V, Polderman N, Renken-Terhaerdt J, Paglialonga F, Oosterveld M, Tuokkola J, Anderson C, Desloovere A, Greenbaum L, Haffner D, Nelms C, Qizalbash L, Vande Walle J, Warady B, Shroff R, Rees L (2020) Energy and protein requirements for children with CKD stages 2-5 and on dialysis clinical practice recommendations from the Pediatric Renal Nutrition Taskforce. Pediatr Nephrol 35:519-531

31. Schiller LR, Santa Ana CA, Sheikh MS, Emmett M, Fordtran MD (1989) Effect of the time of administration of calcium acetate on phosphorus binding. N Engl Journal of Med 320:1110-1113

32. Shroff R, Knott C, Rees L (2010) The virtues of vitamin D-but how much is too much? Pediatr Nephrol 25(9):1607-1620

33. Public Health England (2019) NDNS: time trend and income analyses for years 1 to 9 . https://wwwgovuk/government/statistics Accessed 2 Dec 2019
34. Lalayiannis AD, Crabtree NJ, Askiti V, Mitsioni A, Fewtrell M, Biassoni L, Kaur A, Milford DV, Shroff R (2019) Using PQCT to assess the associations of DXA imaging with serum biomarkers in CKD-MBD. Pediatr Nephrol 24:1899-1900

35. Kuhlmann MK (2007) Practical approaches to management of hyperphosphatemia: can we improve the current situation? Blood Purif 25:120-124

36. Blydt-Hansen TM, Pierce CB, Cai Y, Samsonov D, Massengill S, Moxey-Mims M, Warady BA, Furth S (2014) Medication treatment complexity and adherence in children with CKD. CJASN 9(2): $247-254$

37. Ortiz-Andrellucchi A, Henriquez-Sanchez P, Sanches-Villegas A, Pena-Quintana L, Mendez M, Serra-Majem L (2009) Dietary assessment methods for micronutrient intake in infants, children and adolescents: a systematic review. Br J Nutr 102:S87-S211

38. Oenning LL, Vogel J, Calvo MS (1988) Accuracy of methods estimating calcium and phosphorus intake in daily diets. J Am Diet Assoc 88(9):1076-1108

39. Schwartz GJ, Schneider MF, Maier PS, Moxey-Mims M, Dharnidharka VR, Warady BA, Furth SL, Muñoz A (2012) Improved equations estimating GFR in children with chronic kidney disease using an immunonephelometric determination of cystatin C. Kidney Int 82(4):445-453

40. Shroff R, Wan W, Nagler E, Bakkaloglu S, Fischer DC, Bishop N, Cozzlino M, Bacchetta J, Edefonti A, Stefanidid CJ, Vande Walle J. Haffner D, Klaus G, Schmitt CP (2017) Clinical practice recommendations for native vitamin $\mathrm{D}$ therapy in children with chronic kidney disease stages 2-5 and on dialysis. Nephrol Dial Transplant 32 (7):1098-1113

Publisher's note Springer Nature remains neutral with regard to jurisdictional claims in published maps and institutional affiliations. 